\title{
CORRECTION
}

\section{Correction to: A wake field design system utilizing a database analysis to enhance the performance of energy saving devices and propeller}

\author{
Yasuo Ichinose $^{1}$ (1) $\cdot$ Yusuke Tahara $^{1}$
}

Published online: 11 September 2019

(C) The Japan Society of Naval Architects and Ocean Engineers (JASNAOE) 2019

Correction to: Journal of Marine Science and Technology https://doi.org/10.1007/s00773-018-0611-x

In the original publication, Table 2 has been published incorrectly. The correct version of Table 2 is provided in this correction.

Table 2 Correspondence of parameters of DB1

\begin{tabular}{lll}
\hline & {$\left[L_{\mathrm{PP}}, B, d\right]$} & {$[\xi, \eta, \zeta]$} \\
\hline (1) & {$[81.0,14.2,3.8]$} & {$[0,0,0]$} \\
(2) & {$[83.0,13.8,3.8]$} & {$[1,0,0]$} \\
(3) & {$[83.0,14.5,3.8]$} & {$[1,1,0]$} \\
(4) & {$[79.0,14.5,3.8]$} & {$[0,1,0]$} \\
(5) & {$[73.0,12.8,4.8]$} & {$[0,0,1]$} \\
(6) & {$[83.0,12.8,4.8]$} & {$[1,0,1]$} \\
(7) & {$[77.0,13.8,4.8]$} & {$[1,1,1]$} \\
(8) & {$[73.0,14.5,4.8]$} & {$[0,1,1]$} \\
\hline
\end{tabular}

Publisher's Note Springer Nature remains neutral with regard to jurisdictional claims in published maps and institutional affiliations.

The original article can be found online at https://doi.org/10.1007/ s00773-018-0611-x.

Yasuo Ichinose

ichinose@nmri.go.jp

1 National Maritime Research Institute, Mitaka, Japan 